\title{
Frailty and adverse outcomes in older adults being discharged from the emergency department: A prospective cohort study
}

\author{
Jonathan Afilalo, MD, MSc*; Salvatore Mottillo, MD, MSc ${ }^{\dagger}$; Xiaoqing Xue, MSc ${ }^{\ddagger}$; \\ Antoinette Colacone, BSc ${ }^{\ddagger}$; José A. Morais, MDף; J. Scott Delaney, MD\#; Marc Afilalo, MD ${ }^{\ddagger}$
}

\begin{abstract}
Clinician's Capsule
What is known about the topic?

The 5-meter gait speed test is an objective and efficient test to screen for frailty at the time of ED discharge.

What did this study ask?

Is slow gait speed or weak handgrip strength associated with repeat ED visits and functional decline?

What did this study find?

Two of five older adults leaving the ED were found to have slow 5-meter gait speed using a cutoff of 6 seconds or more, which was associated with higher risks of functional decline and subsequent ED visits.

Why does this study matter to clinicians?

Adverse events could potentially be mitigated by referring slow walkers for further geriatric assessment and interventions.
\end{abstract}

\section{ABSTRACT}

Background: A growing number of frail older adults are treated in the emergency department (ED) and discharged home. There is an unmet need to identify older adults that are predisposed to functional decline and repeat ED visits so as to target them with proactive interventions.

Methods: A prospective cohort study was conducted in patients 75 years or older who were being discharged from the ED. The objective was to test the value of frailty screening tests, namely 5-meter gait speed and handgrip strength, to predict repeat ED visits at 1 and 6 months and functional decline at 1 month using multivariable logistic regression.

Results: After excluding 7 patients lost to follow-up, 150 patients were available for analysis. The mean age was 81.1 \pm 4.9 years with $51 \%$ females, $13 \%$ arriving by ambulance, and $67 \%$ having at least two comorbid conditions. At ED discharge, $41 \%$ of patients were found to have slow gait speed, whereas $23 \%$ had weak handgrip strength. After adjustment, only slow gait speed was independently associated with functional decline at 1 month (odds ratio [OR] 1.39 per 0.1 meters/ second decrement, $95 \%$ confidence interval [Cl], 1.12 to 1.72 ) and repeat ED visits at 6 months (OR 1.20 per 0.1 meters/ second decrement, $95 \% \mathrm{Cl}, 1.01$ to 1.42 ).

Conclusions: Gait speed can be feasibly measured at the time of ED discharge to identify frail older adults at risk for early functional decline and subsequent return to the ED. Conversely, grip strength was not found to be associated with functional decline or ED visits.

\section{RÉSUMÉ}

Contexte: Un nombre croissant de personnes âgées fragiles obtiennent leur congé et retournent à domicile après avoir été traitées au service des urgences (SU). Toutefois, il faudrait trouver un moyen de reconnaitre les personnes âgées prédisposées à une perte d'autonomie et à des consultations à répétition au SU afin de les cibler et d'intervenir de manière proactive.

Méthode: Il s'agit d'une étude de cohortes prospective, menée chez des personnes âgées de 75 ans et plus ayant obtenu leur congé du SU. L'objectif était d'évaluer la qualité des tests de dépistage de la fragilité, soit la vitesse de déambulation sur 5 mètres et la force de préhension, comme facteurs prévisionnels de consultations à répétition au $\mathrm{SU}$ au bout de 1 mois et de 6 mois, et de la perte d'autonomie au bout de 1 mois, à I'aide d'une analyse de régression logistique plurifactorielle. Résultats: Après l'exclusion de 7 malades perdus de vue en cours de suivi, il restait en tout 150 patients qui ont participé à l'étude. L'âge moyen s'élevait à $81,1 \pm 4,9$ ans; les sujets se caractérisaient comme suit : $51 \%$ étaient des femmes; $13 \%$

From: *Division of Cardiology and Centre for Clinical Epidemiology, Jewish General Hospital, McGill University, Montreal, OC; ${ }^{\dagger}$ Division of Emergency Medicine, Hôpital Pierre-Le Gardeur, Terrebonne, QC; ${ }^{\ddagger}$ Department of Emergency Medicine, Jewish General Hospital, McGill University, Montreal, QC; "Division of Geriatric Medicine and Research Institute of the McGill University Health Centre, McGill University, Montreal, QC; and the \#Division of Emergency Medicine, McGill University Health Centre, McGill University, Montreal, OC.

Correspondence to: Dr. Jonathan Afilalo, Director, Geriatric Cardiology Fellowship Program, Jewish General Hospital, McGill University, 3755 Cote Ste Catherine Road, E-222, Montreal, QC; Email: jonathan.afilalo@mcgill.ca

(c) Canadian Association of Emergency Physicians

CJEM 2020;22(1):65-73

DOI 10.1017/cem.2019.431 
sont arrivés en ambulance et $67 \%$ étaient atteints d'au moins deux affections concomitantes. Au moment du congé du SU, $41 \%$ des sujets avaient une vitesse de déambulation lente et $23 \%$, une force de préhension faible. Après rajustement de certaines variables, seule la vitesse de déambulation s'est révélée un facteur indépendant associé à la perte d'autonomie au bout de 1 mois (risque relatif approché [RRA] : 1,39 par tranche de 0,1 mètre/seconde; IC à $95 \%: 1,12$ à 1,72) et aux consultations à répétition au $\mathrm{SU}$ au bout de 6 mois (RRA : 1,20 par tranche de 0,1 mètre/seconde; IC à $95 \%: 1,01$ à 1,42 ).
Conclusions: Le test de la vitesse de déambulation peut s'effectuer facilement avant le congé du SU afin de bien reconnaître les personnes âgées fragiles sujettes à une perte d'autonomie précoce et à des consultations ultérieures au SU. À l'inverse, la force de préhension n'était pas associée à la perte d'autonomie ou à des consultations à répétition au SU.

Keywords: Disability, emergency department, frailty

\section{INTRODUCTION}

Frailty is a geriatric syndrome characterized by impaired resilience to stressors and adverse health outcomes. ${ }^{1}$ The emergency department (ED) is the receiving ground for patients suffering acute stressors, and despite effective stabilization and discharge, frail patients often do not regain their baseline functional status and they return to the ED for new or unresolved issues. With older adults being the most rapidly growing group of patients encountered in the $\mathrm{ED},{ }^{2-4}$ and the most likely to be frequent attenders, ${ }^{5}$ there is an opportunity to screen for frailty and initiate interventions that may mitigate adverse outcomes. These interventions may include pathways for rapid follow-up by primary care providers, referral to outpatient geriatric assessment units, and community-based support services.

While frailty has been integrated in various medical and surgical specialties, adoption has been limited in emergency medicine. ${ }^{6}$ A systematic mapping review on this topic found that there was a promising body of evidence on the treatment of frail patients in the ED, encompassing changes to ED staffing, physical infrastructure, care delivery, and holistic "geri-ED" models of care. ${ }^{7}$ However, the review found that there was inconclusive evidence to endorse the use of any specific tool to identify frail patients in the ED, with most studies using rapid case finding questionnaires, checklists of accumulated deficits, or patient-reported assessments of the frailty phenotype. The latter is typically operationalized as a combination of slow gait speed, weak handgrip strength, low habitual physical activity, exhaustion, and weight loss. ${ }^{8}$

Rather than asking patients to describe their walking and strength abilities as previously done, we sought to improve the identification of frailty by objectively measuring central components of the frailty phenotype, ${ }^{9}$ namely, gait speed and grip strength, at the time of ED discharge. Both of these tests have been extensively validated in older adults, and gait speed has been shown to be the screening test with the highest combined sensitivity and specificity to identify frailty in the community. ${ }^{10}$ However, little is known about the use of gait speed to identify frailty in the ED. The current study was conducted to address this knowledge gap and test the hypothesis that simple objective physical performance tests would be associated with functional decline and repeat visits following ED discharge.

\section{METHODS}

\section{Study design and population}

This report is a prospective cohort study conducted between 2014 and 2016 at the Jewish General Hospital ED in Montreal, Quebec. Patients 75 years or older were approached by trained research professionals before ED discharge and invited to complete a questionnaire, grip strength test, and 5 -meter gait speed test ${ }^{11}$ (Supplemental Table 1, which is available online) to assess their level of frailty and disability. Caregivers and family members were encouraged to be present to contribute their input about the patients' baseline functional status and living situation. After ED discharge, patients were contacted to reassess their level of disability and re-visits to the ED. Electronic medical records were reviewed by to extract clinical covariates. Institutional ethics approval was obtained, and participants provided informed consent. Excluded were those with prohibitive language barriers, severe neuropsychiatric impairments (severe dementia, active delirium, unstable psychiatric 
condition), acute lower limb injuries that impeded walking, and arrival from full-care assisted living or rehabilitation facilities. Eligible patients were approached during daytime hours on weekdays, representing a convenience sample within the constraints of our research assistants' availability. The treating physicians and patients were blinded to the frailty test results so as not to influence their decision to proceed with the planned discharge from the ED or alter the postdischarge plan.

\section{Outcome measures}

The outcomes of interest were unplanned repeat ED visit and postdischarge functional decline. Repeat ED visits were ascertained at 1 and 6 months using a combination of telephone contact with the patients and their family members and a review of the electronic medical records at the Jewish General Hospital. Unplanned visits excluded those that were scheduled or requested by the clinician for specific testing. Functional decline was ascertained using a 13-item disability questionnaire consisting of six basic activities of daily living (ADL; Katz Index $)^{12}$ and seven instrumental activities of daily living (IADL; Older Americans Resources and Services scale) ${ }^{13}$ administered at baseline and by telephone interview 1 month after ED discharge. The number of ADL and IADL items for which help was required (partial or total dependency) was summed to calculate the disability score, ranging from 0 to 13 points. Whereas different scoring schemes for disability have been proposed, this simplified scheme is commonly used and has acceptable psychometric properties. ${ }^{14}$ An increase of one or more points from baseline to follow-up was defined $a d$ boc as a clinically meaningful functional decline. ${ }^{14}$ The research assistants administering the follow-up questionnaire were blinded to the baseline frailty test results.

\section{Statistical analysis}

The distributions of gait speed and grip strength were examined using histograms and summary statistics. Unadjusted associations were evaluated using chi-squared and student t-tests. Adjusted associations were evaluated using logistic regression models. To avoid overfitting, parsimonious models were a priori adjusted for age, female sex, white race, Functional Comorbidity Index (FCI), ${ }^{15}$ ambulance arrival, final diagnosis, and either gait speed or grip strength. Final diagnosis was categorized as cardiovascular, gastrointestinal or genitourinary, infectious, musculoskeletal, or other. The FCI is a composite score encompassing the following 17 comorbidities: angina, myocardial infarction, heart failure, stroke, peripheral arterial disease, diabetes, asthma, chronic obstructive pulmonary disease, gastrointestinal bleed, back disease, arthritis, osteoporosis, depression, anxiety, visual impairment, hearing impairment. Obesity was not included because body mass index was not systematically collected. This study was powered with an alpha of 0.05 and beta of 0.80 to detect a twofold increase in repeat ED visits in frail patients, assuming a baseline rate of $20 \%$ and an even proportion of frail and nonfrail patients. Analyses were performed with the STATA 14 software package (College Station, TX).

\section{RESULTS}

\section{Study cohort}

During the study period, 157 patients were enrolled and 7 (4\%) of these were lost to follow-up, leaving 150 patients for analysis in the final cohort (Figure 1). The characteristics of patients who were eligible but nonenrolled were similar to patients who were enrolled (Supplemental Table 2). The mean age was $81.1 \pm 4.9$ years with $76(51 \%)$ females. All patients were able to complete the gait speed and grip strength tests before ED discharge, and there were no testing-related adverse events. The mean grip strength was $28.8 \pm 8.9 \mathrm{~kg}$ (Supplemental Figure 1), with 34 (23\%) being classified as weak. The mean gait speed was $0.93 \pm 0.29$ meters/second (Supplemental Figure 2), with 61 (41\%) being classified as slow ( $<0.83$ meters/second). On aggregate, 71 (47\%) had evidence of frailty based on either slow gait speed and/or weak grip strength ( $<30 \mathrm{~kg}$ for men and $<20 \mathrm{~kg}$ for women).

\section{Baseline characteristics}

Patients that were frail according to either gait speed or grip strength were older (83.5 v. 79.1 years; $p<0.001)$, with a poorer self-reported health rating $(2.4 \mathrm{v} .2 .0$ of $5 ; p=0.002)$, a greater number of ADL/IADL disabilities (1.0 v. 0.2 of $13 ; p<0.001)$, a greater number of FCI comorbidities (3.0 v. 1.9 of $17 ; p<0.001)$ (Table 1 ). The individual comorbidities most frequently observed in frail patients were heart failure, hypertension, arrhythmia, and arthritis. The individual dependencies 


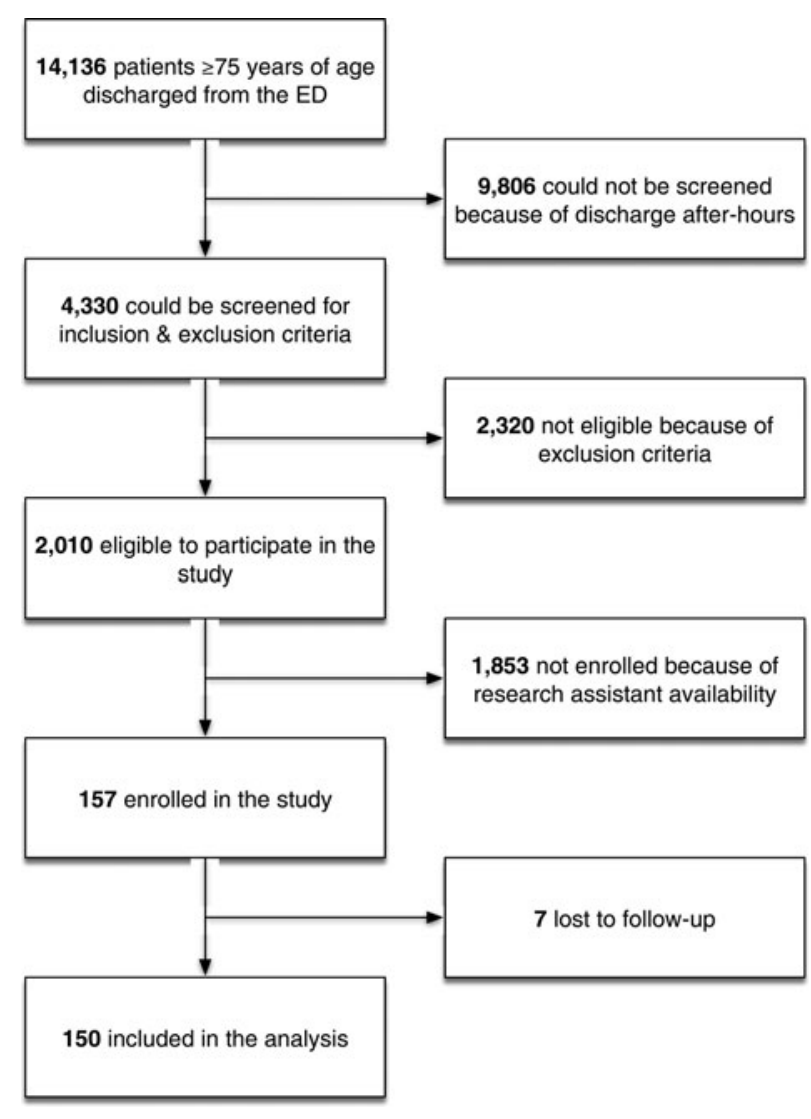

Figure 1. Flow diagram.

most frequently reported by frail patients were requiring help for transportation, shopping, housework, and incontinence (Supplemental Figure 3). Despite these differences, frail patients were not significantly more likely to receive home help services at baseline and had similar modes of ED arrival, triage acuity, length of stay, and final diagnoses.

\section{Unadjusted outcomes}

A total of 29 (19\%) and 45 (30\%) patients had documented unplanned repeat ED visits at 1 and 6 months, respectively, and 36 (25\%) had evidence of functional decline at 1 month (Table 2). Repeat ED visits were not significantly associated with gait speed or grip strength in unadjusted analyses, whereas functional decline was significantly associated with being frail ( $35 \%$ v. $14 \% ; p=0.002)$. Frail patients had a greater number of ADL/IADL disabilities at 1 month (1.4 v. $0.3 ; p<0.001)$ and a trend toward a greater change in number of disabilities from baseline to 1 month $(+0.5$ v. $+0.1 ; p=0.07)$. In turn, there was a trend for functional decline at 1 month to be a risk factor for repeat ED visits at 6 months ( $43 \%$ v. $26 \% ; p=0.06)$.

\section{Adjusted outcomes}

After adjusting for age, sex, race, FCI, ambulance arrival, and final diagnosis, gait speed was independently associated with repeat ED visit at 6 months (odds ratio [OR] 1.20 per 0.1 meters/second decrement, $95 \%$ confidence interval [CI], 1.01 to 1.42 ) and functional decline at 1 month (OR 1.39 per 0.1 meters/second decrement, $95 \% \mathrm{CI}, 1.12$ to 1.72 ) but not with repeat ED visits at 1 month (OR 1.06 per 0.1 meters/second decrement, $95 \%$ CI, 0.88 to 1.27) (Table 3; Figure 2). The HosmerLemeshow goodness-of-fit $p$-values for these models were $0.18,0.18$, and 0.21 , respectively. When dichotomized according to the 6-second cutoff ( 0.83 meters/ second), slow gait speed was independently associated with functional decline at 1 month (OR 3.52; 95\% CI, 1.39 to 8.89 ). In a sensitivity analysis, functional decline at 1 month added to the multivariable model was associated with repeat ED visits at 6 months (OR 2.60; $95 \%$ CI, 1.01, 6.69). Grip strength was not significantly associated with any of these outcomes (Table 4).

\section{DISCUSSION}

Our study has demonstrated that 5-meter gait speed can be feasibly measured at the time of ED discharge to identify frail older adults at risk for functional decline and return to the ED. Two of five older adults leaving the ED were found to be slow walkers, which, compounded on their greater burden of comorbidity and functional disability, increased by threefold their risk of short-term further functional decline. Functional decline was a harbinger for future ED usage over the ensuing 6 months. Gait speed was not predictive of short-term repeat ED visits within the first month after ED discharge. Finally, grip strength was not predictive of functional decline or repeat ED visits; therefore, gait speed should be favored as a screening test for frailty in this setting.

To date, most of the evidence on frailty in the ED has been based on rapid geriatric case finding questionnaires (Identification of Seniors At Risk [ISAR], Triage Risk Screening Tool [TRST], PRISMA-7, Silver Code) and global assessments of accumulated deficits (Frailty Index [FI], Clinical Frailty Scale [CFS], Brief Geriatric Assessment [BGA]). ${ }^{6,7,16,17}$ The case finding 


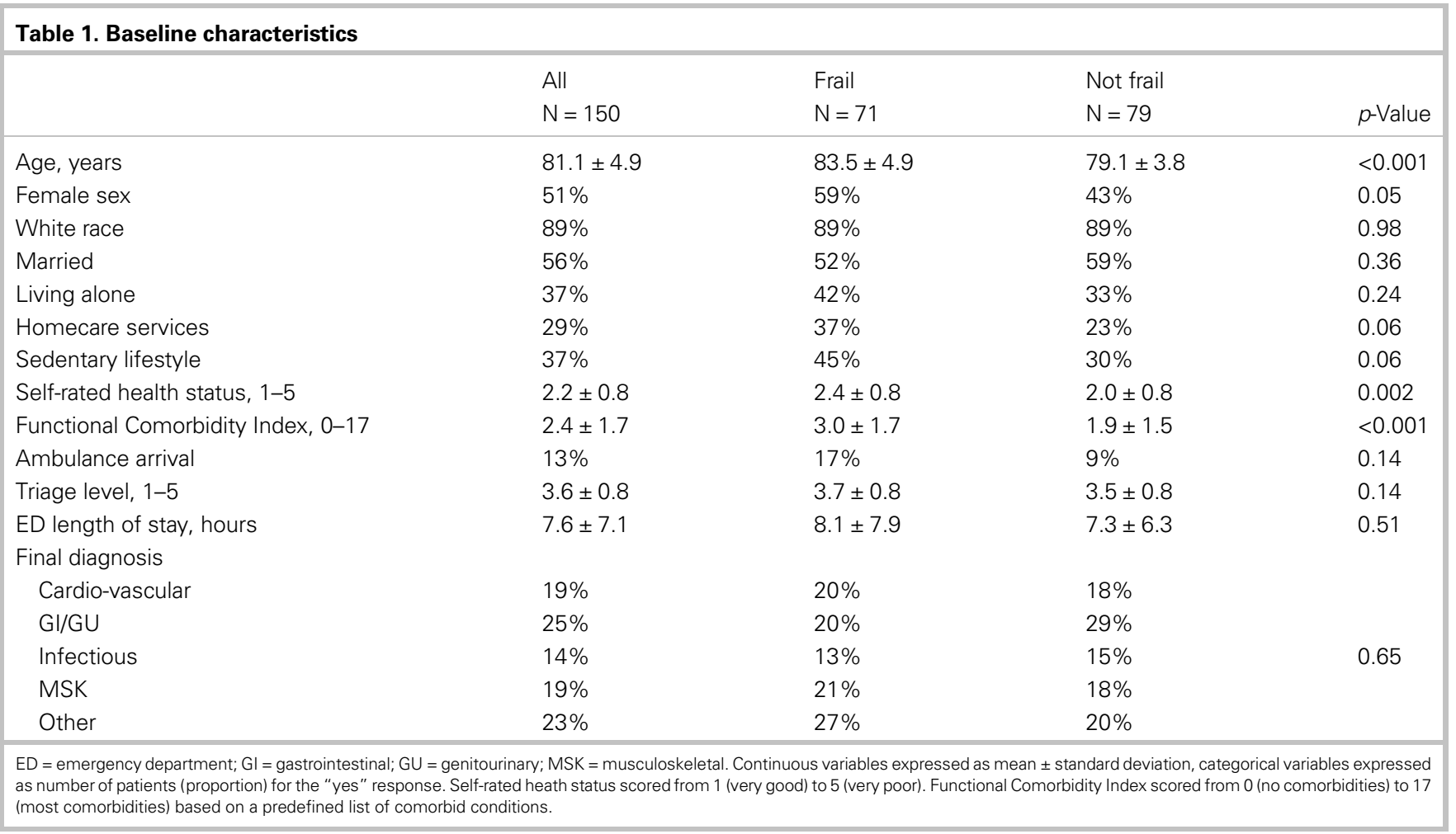

questionnaires are practical for front-line screening at the time of ED triage, ${ }^{18}$ but their specificity to predict adverse outcomes is modest. The FI and CFS are validated predictors of hospital admission, length of stay, death, and functional decline,${ }^{19-23}$ but their practical utility is contingent on being able to collect the required data elements in real-time. ${ }^{24}$ The busy ED clinician can "ballpark" a CFS rating, but this type of

\begin{tabular}{|c|c|c|c|c|}
\hline & $\begin{array}{l}\text { All } \\
N=150\end{array}$ & $\begin{array}{l}\text { Frail } \\
N=71\end{array}$ & $\begin{array}{l}\text { Not Frail } \\
\mathrm{N}=79\end{array}$ & $p$-Value \\
\hline \multicolumn{5}{|l|}{ Repeat ED visit } \\
\hline 1 month & $19 \%$ & $19 \%$ & $20 \%$ & 0.91 \\
\hline 6 months & $30 \%$ & $25 \%$ & $35 \%$ & 0.19 \\
\hline \multicolumn{5}{|l|}{ Disability score } \\
\hline Baseline & $0.6 \pm 1.2$ & $0.2 \pm 0.8$ & $1.0 \pm 1.5$ & $<0.001$ \\
\hline 1 month & $0.8 \pm 1.7$ & $0.3 \pm 0.9$ & $1.4 \pm 2.1$ & $<0.001$ \\
\hline Functional decline & $24 \%$ & $14 \%$ & $35 \%$ & 0.002 \\
\hline \multicolumn{5}{|c|}{$\begin{array}{l}\text { ED }=\text { emergency department. Continuous variables expressed as mean } \pm \text { standard } \\
\text { deviation, categorical variables expressed as number of patients (proportion) for the "yes" } \\
\text { response. Disability scored from } 0 \text { (no disabilities) to } 13 \text { (most disabilities) based on the } \\
\text { number of ADLs and IADLs that the patient reported being unable to perform without } \\
\text { help. }\end{array}$} \\
\hline
\end{tabular}

rating is poorly reproducible ${ }^{25}$ and no better than subjective judgment. ${ }^{26}$

Phenotypic assessments of frailty, particularly those based on physical tests, are objective and generalizable across clinicians and institutions. ${ }^{9}$ This is pertinent in the ED where clinicians have limited time for questionnaires, acutely ill patients may have limited ability for recall, and over time, a given patient may visit multiple different EDs and be seen by a variety of clinicians. However, acutely ill patients may have limited ability to complete physical tests and the resulting scores may not be indicative of their true capabilities. Fallon et al. cited this concern to justify why their prospective cohort study failed to observe an association between frailty and mortality in ED patients, with frailty having been measured by a questionnaire and grip strength test. ${ }^{27}$ Tucker et al. sought to pilot test the feasibility of the gait speed test by ED nurses, and although the nurses agreed that "gait speed screening should be implemented in the ED as a standard of care for older patients," they managed to collect these data in only $21 / 35$ patients. ${ }^{28}$

Sirois et al. attempted to circumvent the ED patients' acute physical limitations by asking them to self-rate their lower-extremity strength, energy, and weight 
Jonathan Afilalo et al.

\begin{tabular}{|c|c|c|c|}
\hline & \multicolumn{2}{|l|}{ Repeat ED visit } & \multirow{3}{*}{$\begin{array}{l}\text { Functional decline } \\
\text { OR (95\% Cl; p-value) }\end{array}$} \\
\hline & 1 Month & 6 Months & \\
\hline & OR (95\% Cl; p-value) & OR (95\% Cl; p-value) & \\
\hline Age & $0.9(0.8,1.02 ; 0.11)$ & $0.95(0.9,1.04 ; 0.29)$ & $1.01(0.9,1.1 ; 0.79)$ \\
\hline Female sex & $0.9(0.3,2.2 ; 0.75)$ & $0.7(0.3,1.6 ; 0.37)$ & $0.7(0.3,1.6 ; 0.36)$ \\
\hline White race & 1.0 (omitted) & $4.3(0.9,20.9 ; 0.07)$ & $1.4(0.4,5.3 ; 0.65)$ \\
\hline $\mathrm{FCl}$, per 1 comorbidity & $0.9(0.7,1.3 ; 0.59)$ & $0.9(0.7,1.2 ; 0.39)$ & $1.1(0.8,1.4 ; 0.57)$ \\
\hline Ambulance arrival & $2.8(0.8,9.9 ; 0.11)$ & $2.3(0.7,7.2 ; 0.15)$ & $0.3(0.1,1.4 ; 0.13)$ \\
\hline \multicolumn{4}{|l|}{ Diagnosis } \\
\hline Cardio-vascular & 1.0 (referent) & 1.0 (referent) & 1.0 (referent) \\
\hline $\mathrm{GI} / \mathrm{GU}$ & $0.2(0.03,0.8 ; 0.03)$ & $0.3(0.1,1.06 ; 0.06)$ & $2.8(0.8,10.1 ; 0.12)$ \\
\hline Infectious & $0.7(0.2,2.2 ; 0.50)$ & $0.9(0.3,2.5 ; 0.83)$ & $1.9(0.5,6.4 ; 0.33)$ \\
\hline MSK & $0.6(0.2,2.6 ; 0.53)$ & $0.8(0.2,2.7 ; 0.68)$ & $0.96(0.2,4.7 ; 0.96)$ \\
\hline Other & $0.5(0.2,1.8 ; 0.30)$ & $0.5(0.1,1.4 ; 0.17)$ & $1.1(0.3,4.0 ; 0.91)$ \\
\hline Gait speed, per $\downarrow 0.1 \mathrm{~m} / \mathrm{s}$ & $1.1(0.9,1.3 ; 0.55)$ & $1.2(1.01$ to $1.4 ; 0.04)$ & $1.4(1.1$ to $1.7 ; 0.003)$ \\
\hline
\end{tabular}

loss, ${ }^{26}$ finding this to be predictive of functional decline 3-6 months after an ED visit for a minor injury. MartinSanchez et al. similarly asked patients to self-rate their gait speed, upper-extremity strength, activity, energy, and weight loss, finding this to be predictive of 30-day mortality after an ED visit for decompensated heart failure. ${ }^{29}$ Despite these two promising studies, Stiffler et al. reported the accuracy of self-rated gait speed and grip strength to be weak in ED patients and concluded that objective measurements should be favored. ${ }^{30}$ A systematic review by Eagles et al. did not identify any highquality studies using gait speed as a quantitative

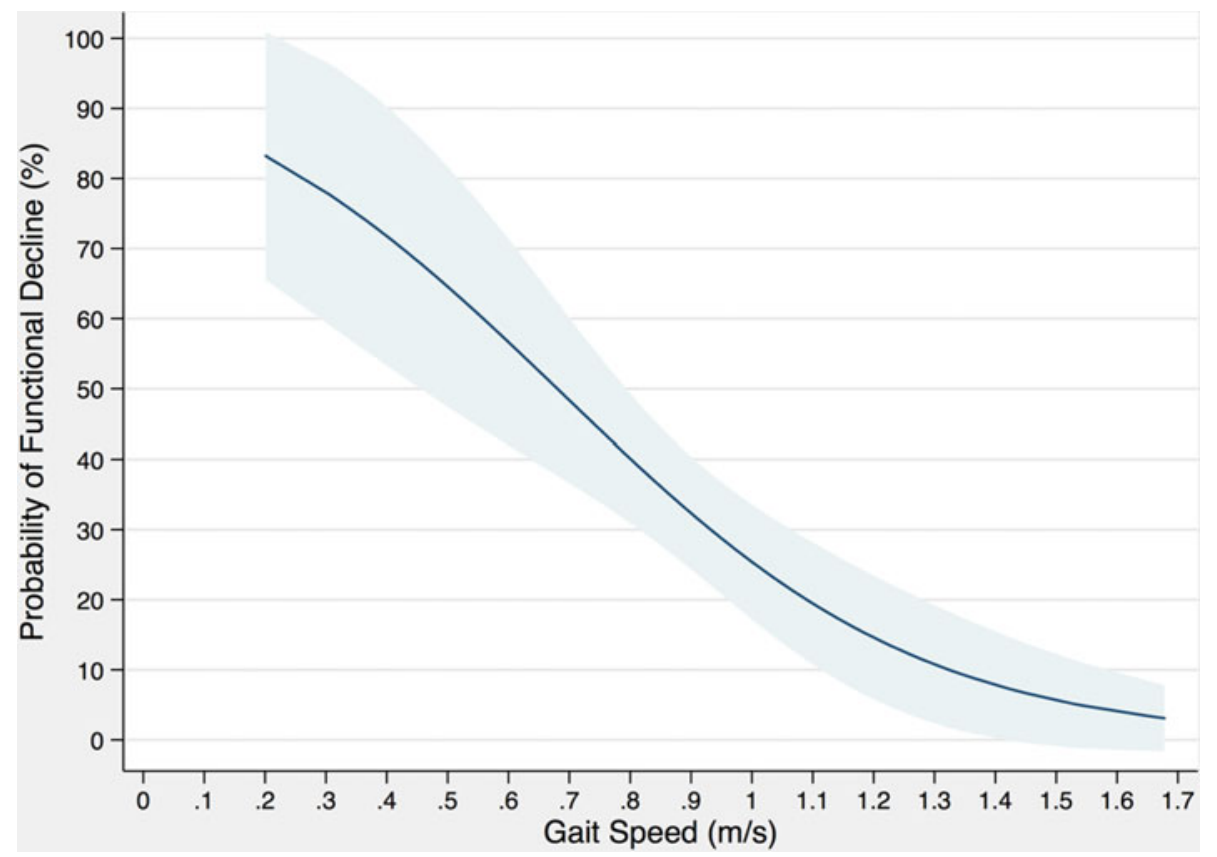

Figure 2. Adjusted association between gait speed and incident functional decline. Slower gait speeds were associated with higher probabilities of functional decline. Functional decline was defined as one or more new disabilities for basic or instrumental activities of daily living 1-month after ED discharge. 


\begin{tabular}{|c|c|c|c|}
\hline & \multicolumn{2}{|l|}{ Repeat ED visit } & \multirow{3}{*}{$\begin{array}{l}\text { Functional decline } \\
\text { OR (95\% Cl; p-value) }\end{array}$} \\
\hline & 1 Month & 6 Months & \\
\hline & OR (95\% Cl; p-value) & OR (95\% Cl; p-value) & \\
\hline Age & $0.9(0.8,1.02 ; 0.13)$ & $0.97(0.9,1.1 ; 0.54)$ & $1.1(0.98,1.2 ; 0.11)$ \\
\hline Female sex & $0.8(0.2,2.9 ; 0.71)$ & $0.4(0.1,1.4 ; 0.15)$ & $0.6(0.2,2.1 ; 0.46)$ \\
\hline White race & 1.0 (omitted) & $4.2(0.9,20.3 ; 0.08)$ & $1.2(0.3,4.2 ; 0.83)$ \\
\hline $\mathrm{FCl}$, per 1 comorbidity & $0.95(0.7,1.3 ; 0.74)$ & $1.0(0.8,1.3 ; 0.98)$ & $1.3(0.996,1.6 ; 0.05)$ \\
\hline Ambulance arrival & $2.6(0.8,8.9 ; 0.13)$ & $1.8(0.6,5.4 ; 0.31)$ & $0.3(0.1,1.2 ; 0.09)$ \\
\hline \multicolumn{4}{|l|}{ Diagnosis } \\
\hline Cardio-vascular & 1.0 (referent) & 1.0 (referent) & 1.0 (referent) \\
\hline GI/GU & $0.2(0.03,0.8 ; 0.03)$ & $0.3(0.1,1.04 ; 0.06)$ & $2.0(0.6,6.6 ; 0.28)$ \\
\hline Infectious & $0.7(0.2,2.1 ; 0.46)$ & $0.8(0.3,2.3 ; 0.71)$ & $1.3(0.4,4.2 ; 0.64)$ \\
\hline MSK & $0.6(0.2,2.5 ; 0.49)$ & $0.7(0.2,2.3 ; 0.51)$ & $0.6(0.1,2.8 ; 0.53)$ \\
\hline Other & $0.5(0.2,1.9 ; 0.32)$ & $0.5(0.2,1.5 ; 0.19)$ & $0.99(0.3,3.5 ; 0.99)$ \\
\hline Grip strength, per $\downarrow 1 \mathrm{~kg}$ & $1.01(0.9,1.1 ; 0.73)$ & $1.1(0.99,1.1 ; 0.13)$ & $1.03(0.96$ to $1.1 ; 0.41)$ \\
\hline
\end{tabular}

assessment in the ED; moreover, nonquantitative assessments of mobility (mainly the "Get Up \& Go" test) were not predictive of hospital admissions or ED visits. ${ }^{31}$ Thus, the current study was designed to objectively measure gait speed in the ED and demonstrate its feasibility and prognostic value.

Several limitations merit discussion. First, this was a single-center study that should be confirmed by a larger multi-center study before recommending gait speed for widespread use. It should be noted that gait speed has been validated in acute care settings outside of the ED, including medical wards and cardiovascular units. ${ }^{32}$ While gait speed has been shown to outperform more elaborate frailty scales to predict adverse outcomes, ${ }^{33,34}$ it remains a screening test, and broader assessments are required to capture the multiple facets of frailty. Second, this study used research assistants to measure gait speed during working hours and did not test the implementation by clinical staff during all hours. Although this may affect the generalizability of our results, it is unlikely to have introduced a selection bias because enrolled and nonenrolled patients were generally similar and the reasons for not approaching patients were often logistical in nature. Third, ED visits were ascertained by reviewing medical records at the study center and interviewing patients by phone, such that a minority of ED visits occurring at other centers and not recalled by patients may have been missed leading to a nondifferential information bias. Fourth, the number of covariates analyzed in relation to the number of events for repeat ED visits (mainly at 1 month) may have led to residual confounding or overfitting. ${ }^{35}$ Lastly, the downstream effect of testing for frailty was not assessed and will require dedicated intervention studies. A systematic review identified 18 intervention studies focused on comprehensive geriatric assessment and delivery of care during the ED stay, although few studies addressed the optimization of care after the ED discharge.

\section{CONCLUSIONS}

Five-meter gait speed is an objective low-cost test to screen for frailty before ED discharge. Slow walkers have an increased risk of functional decline and subsequent $\mathrm{ED}$ visits within 6 months. These adverse events could potentially be mitigated by referring slow walkers for further geriatric assessment and interventions to improve their functional status and provide them with the necessary support services at home. While interventions for frail older adults have been successfully deployed in the fields of primary care and rehabilitation medicine, ${ }^{36}$ it remains to be determined how to best connect frail ED patients with the community-based resources that they require to reduce their risk of functional decline and frequent ED visits.

Supplementary material: The supplementary material for this article can be found at https://doi.org/10.1017/cem.2019.431.

Presentations: This work was presented at Canadian Association of Emergency Physicians (CAEP) annual conference in 2015, Edmonton, Alberta. 
Financial support: This work was supported in part by the Jewish General Hospital Foundation. Dr. Jonathan Afilalo is supported by grants from the Fonds de recherche du Québec en Santé and Canadian Institutes of Health Research.

Competing interests: The authors (J.A., S.M., XX., A.C., J.A.M., J.S.D., M.A.) declare that there is no conflict of interest.

\section{REFERENCES}

1. Clegg A, Young J, Iliffe S, Rikkert MO, Rockwood K. Frailty in elderly people. Lancet 2013;381(9868):752-62.

2. Pines JM, Mullins PM, Cooper JK, Feng LB, Roth KE. National trends in emergency department use, care patterns, and quality of care of older adults in the United States. $7 \mathrm{Am}$ Geriatr Soc 2013;61(1):12-7.

3. Latham LP, Ackroyd-Stolarz S. Emergency department utilization by older adults: a descriptive study. Can Geriatr 7 2014;17(4):118-25.

4. Lowthian J, Curtis A, Stoelwinder J, McNeil J, Cameron P. Emergency demand and repeat attendances by older patients. Intern Med 7 2013;43(5):554-60.

5. Street M, Berry D, Considine J. Frequent use of emergency departments by older people: a comparative cohort study of characteristics and outcomes. Int 7 Qual Health Care 2018;41:309.

6. Theou O, Campbell S, Malone ML, Rockwood K. Older adults in the emergency department with frailty. Clin Geriatr Med 2018;34(3):369-86.

7. Preston L, Chambers D, Campbell F, Cantrell A, Turner J, Goyder E. What evidence is there for the identification and management of frail older people in the emergency department? A systematic mapping review. Health Serv Deliv Res Southampton (UK): NIHR Fournals Library 2018;6(16):1-142.

8. Fried LP, Tangen CM, Walston J, et al. Frailty in older adults: evidence for a phenotype. 7 Gerontol A Biol Sci Med Sci 2001;56(3):M146-56.

9. Afilalo J. Conceptual models of frailty: the sarcopenia phenotype. Can 7 Cardiol 2016;32(9):1051-5.

10. Clegg A, Rogers L, Young J. Diagnostic test accuracy of simple instruments for identifying frailty in community-dwelling older people: a systematic review. Age Ageing 2015;44(1):148-52.

11. Afilalo J, Alexander KP, Mack MJ, et al. Frailty assessment in the cardiovascular care of older adults. $7 \mathrm{Am}$ Coll Cardiol 2014;63(8):747-62.

12. Katz S, Ford AB, Moskowitz RW, Jackson BA, Jaffe MW. Studies of illness in the aged. The index of ADL: a standardized measure of biological and psychological function. 7AMA 1963;185:914-9.

13. Fillenbaum GG, Smyer MA. The development, validity, and reliability of the OARS multidimensional functional assessment questionnaire. 7 Gerontol 1981;36(4):428-34.

14. Suijker JJ, van Rijn M, Riet Ter G, Moll van Charante EP, de Rooij SE, Buurman BM. Minimal important change and minimal detectable change in activities of daily living in communityliving older people. $\mathcal{F}$ Nutr Health Aging 2017;21(2):165-72.

15. Groll DL, To T, Bombardier C, Wright JG. The development of a comorbidity index with physical function as the outcome. 7 Clin Epidemiol 2005;58(6):595-602.
16. Launay CP, de Decker L, Kabeshova A, Annweiler C, Beauchet O. Risk of unplanned emergency department readmission after an acute-care hospital discharge among geriatric inpatients: results from the Geriatric EDEN Cohort study. 7 Nutr Health Aging 2016;20(2):210-7.

17. Beauchet $\mathrm{O}$, Fung S, Launay CP, et al. Predicting a long hospital stay after admission to a geriatric assessment unit: results from an observational retrospective cohort study. Maturitas 2018;115:110-4.

18. Bullard MJ, Melady D, Emond M, et al. Guidance when applying the Canadian Triage and Acuity Scale (CTAS) to the geriatric patient: executive summary. CFEM 2017;19 (S2):S28-S37.

19. Hastings SN, Purser JL, Johnson KS, Sloane RJ, Whitson HE. Frailty predicts some but not all adverse outcomes in older adults discharged from the emergency department. 7 Am Geriatr Soc 2008;56(9):1651-7.

20. Salvi F, Morichi V, Grilli A, et al. Screening for frailty in elderly emergency department patients by using the Identification of Seniors At Risk (ISAR). $\mathcal{f}$ Nutr Health Aging 2012;16(4):313-8.

21. Wallis SJ, Wall J, Biram RW, Romero-Ortuno R. Association of the clinical frailty scale with hospital outcomes. Q7M 2015;108(12):943-9.

22. Provencher V, Sirois MJ, Émond M, et al. Frail older adults with minor fractures show lower health-related quality of life (SF-12) scores up to six months following emergency department discharge. Health Qual Life Outcomes 2016;14(1):40.

23. Brousseau AA, Dent E, Hubbard R, et al. Identification of older adults with frailty in the emergency department using a frailty index: results from a multinational study. Age Ageing 2018;47(2):242-8.

24. Searle SD, Mitnitski A, Gahbauer EA, Gill TM, Rockwood K. A standard procedure for creating a frailty index. BMC Geriatr 2008;8(1):24.

25. Bouillon K, Kivimäki M, Hamer M, et al. Measures of frailty in population-based studies: an overview. BMC Geriatr 2013;13(1):64.

26. Sirois MJ, Griffith L, Perry J, et al. Measuring frailty can help emergency departments identify independent seniors at risk of functional decline after minor injuries. 7 Gerontol A Biol Sci Med Sci 2017;72(1):68-74.

27. Fallon A, Kilbane L, Briggs R, et al. Screening for frailty in older emergency department patients: the utility of the Survey of Health, Ageing and Retirement in Europe Frailty Instrument. Q7M 2018;111(3):151-4.

28. Tucker PW, Evans DD, Clevenger CK, Ardisson M, Hwang U. Feasibility of nurses measuring gait speed in older community-dwelling emergency department patients. Geriatr Nurs 2016;37(6):453-7.

29. Martín-Sánchez FJ, Rodríguez-Adrada E, Mueller C, et al. The effect of frailty on 30-day mortality risk in older patients with acute heart failure attended in the emergency department. Acad Emerg Med 2016;24(3):298-307.

30. Stiffler KA, Finley A, Midha S, Wilber ST. Frailty assessment in the emergency department. F Emerg Med 2013;45(2):291-8.

31. Eagles D, Yadav K, Perry JJ, Sirois MJ, Emond M. Mobility assessments of geriatric emergency department patients: a systematic review. CFEM 2018;20(3):353-61. 
32. Peel NM, Kuys SS, Klein K. Gait speed as a measure in geriatric assessment in clinical settings: a systematic review. 7 Gerontol A Biol Sci Med Sci 2013;68(1):39-46.

33. Purser JL, Kuchibhatla MN, Fillenbaum GG, Harding T, Peterson ED, Alexander KP. Identifying frailty in hospitalized older adults with significant coronary artery disease. 7 Am Geriatr Soc 2006;54(11):1674-81.

34. Afilalo J, Mottillo S, Eisenberg MJ, et al. Addition of frailty and disability to cardiac surgery risk scores identifies elderly patients at high risk of mortality or major morbidity. Circ Cardiovasc Qual Outcomes 2012;5(2):222-8.

35. Vittinghoff E, McCulloch CE. Relaxing the rule of ten events per variable in logistic and Cox regression. Am 7 Epidemiol 2007;165(6):710-8.

36. Bibas L, Levi M, Bendayan M, Mullie L, Forman DE, Afilalo J. Therapeutic interventions for frail elderly patients: part I. Published randomized trials. Prog Cardiovasc Dis 2014;57(2):134-43. 